\title{
Morphological variability of Indonesian rice germplasm and the associated SNP markers
}

\author{
Puji Lestari*, Dwinita Wikan Utami, Ida Rosdianti, Muhamad Sabran \\ Indonesian Center for Agricultural Biotechnology and Genetic Resources Research and Development-IAARD, JI. Tentara Pelajar, \\ No.3A Bogor 16111, Indonesia
}

\section{A B S T R A C T}

\begin{abstract}
Morphological and molecular characterization of rice genotypes with varied genetic background is highly considerable to be carried out to their utilization and to genetic variability incorporation into rice breeding program. In this study, the diversity within 60 rice genotypes from different subspecies of indica, japonica and tropical japonica was analyzed for 19 morphological traits and 384-plex SNPs with GoldenGate assay. Principal component analysis (PCA) clustered the germplasm into three main groups (indica, indica/tropical japonica/ japonica and indica/tropical japonica). PCA axes 1 and 2 and morphological traits with eigenvalue at arbitrary above 0.2 , explained $24.60 \%$ of total variation in the rice germplasm. Seven traits (leaf color, leaf sheats color, ligule color, diameter of basal internode, culm color, ligule length, and flag leaf angle) could be the potential traits as descriptors for further characterization and conservation studies in Indonesian rice germplasm. Based on total morphological traits and 384 SNPs, two major clades were generated and differentiated most genotypes into subspecies/cultivar group according to their individual genetic background. Of total 154 SNPs associated with 15 morphological traits, approximately 48 SNPs were highly significant associated with quantitative and quantitative traits. The associated SNPs which were located inside or very near to genes of interest/QTLs would be potential as genetic markers. These alleles could provide breeders to effectively identify, track and incorporate regions of chromosomes governing the desired morphological traits to improve rice varieties in Indonesia.
\end{abstract}

Keywords: Indonesian rice; Morphological trait; Principal component analysis; SNP

\section{INTRODUCTION}

Rice (Oryza sativa L.) is widely grown in the world to diet billions people living in the subtropics and tropics. The crop will continue to remain a main source of daily food by growing population in many regions (Sasaki, 2002) and contributes toward food security not only in the world but also in Indonesia. In Indonesia, even though national rice production increases significantly in comparison with that of one decade ago (Tobias et al., 2012), consumption of rice has continued to rise per annum. The high demand of rice leads to put higher efforts since this crop has high nutritional value, providing $20 \%$ of calories, $15 \%$ of proteins, minerals and fibers, and a part as animal feed. To increase rice production in Indonesia by the use of a wide range of technologies, an optimal utilize of rice germplasm collection should be addressed to support breeding program.
Rice germplasm in Indonesia including improved varieties (such as upland, lowland and swamp cultivation), hybrid, local accessions, and other breeding status is an important source of useful genes and can be used for crossing parents for desired traits (Zeng et al., 2003). The germplasm is a national asset that needs to be preserved for breeding materials. Development of rice varieties with important traits such as productivity, resistance/tolerance to abiotic and biotic stresses needs broad genetic diversity. Consequently, successful breeding program should consider genetic diversity of rice to improve variety with desired traits of economic importance. High yielding rice varieties along with other superior traits such as resistance to pest and disease, early maturity, grain quality and tolerance to drought, salinity and lodging have been infused for surviving in harsh environments in Indonesia (Silitonga, 2010). A well characterized germplasm with genetic different could be useful for their effective utilization. Genetic

\footnotetext{
*Corresponding author:

Puji Lestari, Indonesian Center for Agricultural Biotechnology and Genetic Resources Research and Development-IAARD, JI. Tentara
} Pelajar, No. 3A Bogor 16111, Indonesia. E-mail: plestari129@yahoo.com 
characterization at morphological and molecular level will enable rice breeders to exploit genotypic diversity for conservation and further crop improvement (Thomson et al., 2007; Juansa et al., 2012; Rabara et al., 2015).

Morphological variations are attributable to classify rice that contains two major subspecies, japonica and indica. The typical grains and environment between the two are distinctive. The other subspecies is broad-grained and rives under tropical conditions and possesses specific morphology, called as tropical japonica. Based on the morphology and molecular analyses, scientists also try to sort rice into different number of cultivar groups namely temperate japonica, aromatic, aus etc. (Garris et al., 2004; Glaszmann, 2004). Morphologically, rice differs in growth stages in respect to vegetative characters, leaf, culm, panicle, and seed properties which are important for guiding selection process in breeding.

In addition to phenotypic characters, molecular characterization proves rapid scientific advances and have introduced new techniques for the conservation and protection as well as their broad applications. Potential molecular markers as marker-assisted selection (MAS) gain prominent in rice breeding and offer new opportunities that increase the efficiency of food production (Franco and Hidalgo, 2003). Markers are also currently widely used to provide information of genetic relatedness and linkage/association with important traits and other function. Modern breeding programs will require high-throughput genotyping that can handle large numbers of samples at a low cost (Thomson, 2014).

A new generation of markers based on single nucleotide polymorphisms (SNPs) is now rapidly overtaking previous markers. SNPs are potential to greatly increase the speed and reduce the cost of molecular marker genotyping with high throughput in order to make it feasible to 'mainstream' MAS into conventional breeding program (Thomson et al., 2010). A number of custom SNP sets from low to high density have been developed using different platforms with automated genotyping (Thomson et al., 2010; Utami et al., 2013; Chen et al., 2011; Singh et al., 2015). These efforts will allow more efficient strategies in genotyping for use in a wide range of genetics and breeding applications. Therefore, this study was carried out to assess the morphological diversity of rice genotypes in Indonesia according to rice descriptor from Bioversity International (2007) and to identify SNP markers significantly associated with the morphological traits using GoldenGate 384-plex SNP genotyping assay.

\section{MATERIALS AND METHODS}

\section{Plant materials}

Sixty rice genotypes belonged to the gene bank collection of Indonesian Center for Agricultural Biotechnology and Genetic Resources Research and Development (ICABIOGRAD) under the Indonesian Agency for Agricultural Research and Development (IAARD) were selected for genotyping of custom 384 SNP chip in this study. The genotypes were chosen based on their diverse genetic background depending on subspcies. Based on the botanical features, the 60 genotypes comprised of 46 indica, 5 japonica, and 9 tropical japonica. The indica group included improved varieties, upland, lowland, hybrid, and IR group developed by International Rice Research Institute (IRRI). The list of total rice genotypes used in this study is presented in Table 1.

\section{Morphological characterization}

All genotypes were grown in green house and two individuals of each genotype were planted in pot in three replications. Rice cultivation was managed according to the standard recommendation of rice practices. Nineteen quantitative and qualitative morphological traits were observed from vegetative to generative growth stages to the descriptors for rice (Bioversity International, IRRI and Warda, 2007) and the data were recorded. The following quantitative traits were observed such as leaf length (LLNG), leaf width (LWDT), diameter of basal internode (DBITR), panicle length (PLNG), leaf angle (LAGL), flag leaf angle (FLAGL), secondary branching of panicle (SBP), culm angle (CAGL), and ligule length (LGLNG). While the remaining 10 qualitative traits included leaf blade pubescence (LBPBS), collar color (CCLR), auricle color (ACLR), leaf blade color (LBCLR), leaf sheath color (LSCLR), ligule shape (LSHP), ligule color (LGCLR), culm color (CUCLR), attitude of panicle branch (APB), and panicle axis (PAXS).

\section{4-plex SNP genotyping with GoldenGate assay DNA Isolation}

The healthy leaves of three week-old rice seedling germinated from a single plant of each genotype was harvested, collected and stored in $-80^{\circ} \mathrm{C}$ until use for DNA isolation. Genomic DNA was isolated using the Thermo Scientific King Fisher Plant DNA kits (Qiagen, 2011). The DNA was eluted with $100 \mu \mathrm{l}$ of TE buffer. The concentration and quality of DNA were measured with NanoDrop1000 (Thermo Scientific Co.) on wavelength of 260/280 and 230/280 (Sambrook and Russel, 2001). Each DNA was concentrated with Speedvac and adjusted to final concentration of $50 \mathrm{ng} / \mu \mathrm{l}$ to meet the required recommendation for GoldenGate assay using iScan array (Illumina, San Diego, CA).

GoldenGate assay for 384 SNP chip using iScan array The GoldenGate assay used the customized OPA 384 SNP chip distributed across 12 chromosomes of rice that 
Tabel 1: List of 60 rice genotypes used in this study

\begin{tabular}{|c|c|c|c|c|c|}
\hline Sample & Accession/variety & Subspecies & Sample & Accession/variety & Subspecies \\
\hline Obs 1 & Silugonggo & Indica & Obs 31 & Inpago 4 & Indica \\
\hline Obs 2 & Dodokan & Indica & Obs 32 & Inpago 5 & Indica \\
\hline Obs 3 & BMIP 22 & Japonica & Obs 33 & Inpago 8 & Indica \\
\hline Obs 4 & IRBLSH-s & Japonica & Obs 34 & FIR32-1-1 & Indica \\
\hline Obs 5 & BMIP 40 & Japonica & Obs 35 & S4616-PN-7-5 & Indica \\
\hline Obs 6 & Bio 110 & Indica & Obs 36 & Lestari & Tropical japonica \\
\hline Obs 7 & IR64 & Indica & Obs 37 & Jangkok & Tropical japonica \\
\hline Obs 8 & IR54 & Indica & Obs 38 & Ketan Bubarak & Tropical japonica \\
\hline Obs 9 & IR30 & Indica & Obs 39 & Klengkap & Tropical japonica \\
\hline Obs 10 & IR65 & Indica & Obs 40 & Nona Bokra & Indica \\
\hline Obs 11 & IR42 & Indica & Obs 41 & Madha Kedhi & Indica \\
\hline Obs 12 & IR74 & Indica & Obs 42 & Repong & Tropical japonica \\
\hline Obs 13 & Inpari 1 & Indica & Obs 43 & Bintang & Tropical japonica \\
\hline Obs 14 & Ciherang & Indica & Obs 44 & Beras Merah D3 & Indica \\
\hline Obs 15 & Fatmawati & Indica & Obs 45 & Ins14-82 & Indica \\
\hline Obs 16 & Adan Kelabit & Tropical japonica & Obs 46 & Ins22-124 & Indica \\
\hline Obs 17 & Banun & Tropical japonica & Obs 47 & Ins24-136 & Indica \\
\hline Obs 18 & Pandan Wangi & Tropical japonica & Obs 48 & Bio158-mamol-Dro & Indica \\
\hline Obs 19 & Kinamaze & Japonica & Obs 49 & Bio5-AC-Blas/BLB03=Inpari BLB & Indica \\
\hline Obs 20 & Nipponbare & Japonica & Obs 50 & Bio113-BC-BlasP & Indica \\
\hline Obs 21 & Inpari 2 & Indica & Obs 51 & Bio128-BC-WBC & Indica \\
\hline Obs 22 & Inpari 6 & Indica & Obs 52 & Inpari 30 & Indica \\
\hline Obs 23 & Inpari 12 & Indica & Obs 53 & D1 Beras Merah & Indica \\
\hline Obs 24 & Inpari 16 Pasundan & Indica & Obs 54 & Code & Indica \\
\hline Obs 25 & Inpari 17 & Indica & Obs 55 & BMIP19(IPBM-32-1-3-3) & Indica \\
\hline Obs 26 & Inpari 18 & Indica & Obs 56 & IR84047-24-3-3-3 & Indica \\
\hline Obs 27 & Inpari 28 Kerinci & Indica & Obs 57 & IR82571-581-1-2-3 & Indica \\
\hline Obs 28 & Inpari 30 & Indica & Obs 58 & IRBB7 & Indica \\
\hline Obs 29 & Hipa 5 Ceva & Indica & Obs 59 & IR82571-602-3-2-2 & Indica \\
\hline Obs 30 & Hipa 13 & Indica & Obs 60 & BMIP1-(BMIP46-4-1) & Indica \\
\hline
\end{tabular}

was design in the previous study (Utami et al., 2013). The genotyping was conducted in accordance to the manufacture protocol for plant genome as described by Illumina's BeadArray technology-based GoldenGate (GG) assay (Fan et al., 2003) at the facility of Indonesian Center for Agricultural Biotechnology and Genetic Resources Research and Development (ICABIOGRAD) under the IAARD. This assay was done on a high-resolution confocal scanner (iScan, Illumina) which was able to read the arrays and generated intensity data. Allele calling was performed automatically using Genome Studio v. 2011.1 (Illumina, San Diego, CA). The SNP genotyping scores (Call rates, GeneTrain and GenCall) were exported using GenomeStudio internal tool for subsequent analysis. Genotypes with a GenCall score below 0.25 were assigned as missing.

\section{Data analysis}

Numerical values for all morphological traits were subjected to analysis using XLSTAT program, particularly statistical summary and correlation matrix (Pearson estimate). Principal component analysis (PCA) was generated on ranged data with linear reduction. The PCA was used to view the traits with significant variation in the rice germplasm. Visualizing of PCA cluster was generated using XLSTAT. To fit the PCA cluster visualization, rice genotypes were named following the default instruction in the program instead of the real name of each rice variety/ accession. Consequently, both the rice varieties name and the corresponding new label depicted in the PCA cluster were described (Table 1). Flapjack also facilitated to generate a phylogenetic tree based on genotypic data of 384 SNPs and the 19 morphological traits in total genotypes (Milne et al., 2010) on the basis of similarity matrices. Flapjack program allowed to analyzing both genotypic data containing allele per marker for each genotype and phenotypic information of either numerical or categorical. Association between SNPs and morphological traits were tested with linear mixed model (SAS, 2002).

\section{RESULTS}

\section{Morphological diversity of rice germplasm}

Morphological assessment displayed by 60 rice genotypes in this study revealed variations on qualitative and quantitative characters. An example of morphological characters used 
as descriptors which were observed in total rice genotypes in this study is depicted in Fig. 1. Collar color, ligule shape, and panicle angle were uniform in total genotypes, showing green, 2 cleft and $>90^{\circ}$, respectively. More than $80 \%$ of the genotypes had intermediate of leaf blade pubescence, $<45^{\circ}$ of flag leaf angle, white of auricle, purple lines of leaf sheath color, $<30^{\circ}$ of culm angle, heavy of secondary branching of panicle, and green color of culm. However, a greater variety of this germplasm was identified on leaf angle, leaf blade color, ligule color, and attitude of panicle branch. The mean, maximum and minimum values of five quantitative traits among this germplasm also varied. The mean values of leaf length, leaf width, and panicle length were 40.15, 0.66 and $24.18 \mathrm{~cm}$, respectively. These genotypes possessed wide ranges of basal internode and ligule length, from 0.50 to $0.80 \mathrm{~cm}$ and $1.25-2.60 \mathrm{~cm}$, respectively. The mean and range values of selected five quantitative morphological traits are shown in Table 2.

Pair wise correlations among traits revealed that only few morphological traits had either significant positive or negative correlations. Based on the correlation category from Dancey and Reidy (2004), correlation coefficient of Pearson (Pearson's $r$ ) explained weak to moderate $(0.3<r<0.7)$. Culm angle with leaf blade color $(r=-0.31)$, and leaf width with diameter of basal internode had moderate and weak negative correlations $(r=-0.28)$, respectively. Between leaf sheath pubescence and panicle length $(r=0.38)$, leaf sheath color and culm color $(r=0.38)$, and flag leaf angle and with leaf angle $(r=0.41)$ were moderate positive correlation.

Based on the first 2 principal components (PCs) with eigenvalues greater than 2 and 1.9, principal component analysis (PCA) for the 19 morphological traits explained $24.60 \%$ of total phenotypic variation in the collection. The result from PCA analysis with the first two PCs estimates for the 19 morphological traits to classify the 60 rice genotypes is presented in Table 3. Particularly, PC1 with eigenvalue greater than 2.0 contributed the most of variation on seven traits in the germplasm. The seven traits comprised four qualitative traits (leaf blade color, leaf sheath color, ligule color, and collar color) and three quantitative traits (flag leaf angle, ligule length and diameter of basal internode). Of these characters, negative characters were from flag leaf angle and ligule length. There was a contrast between the diameter of basal internode with a positive loaded value in PC1 but a negative loaded value in PC2. Thus, morphological traits related to leaf could be major descriptor contributing in differentiation of rice germplasm collection (Toshinori, 1991; Shikari et al., 2009).

Relationship between 60 accessions/varieties of rice revealed by cluster analysis is presented in Fig. 2. The
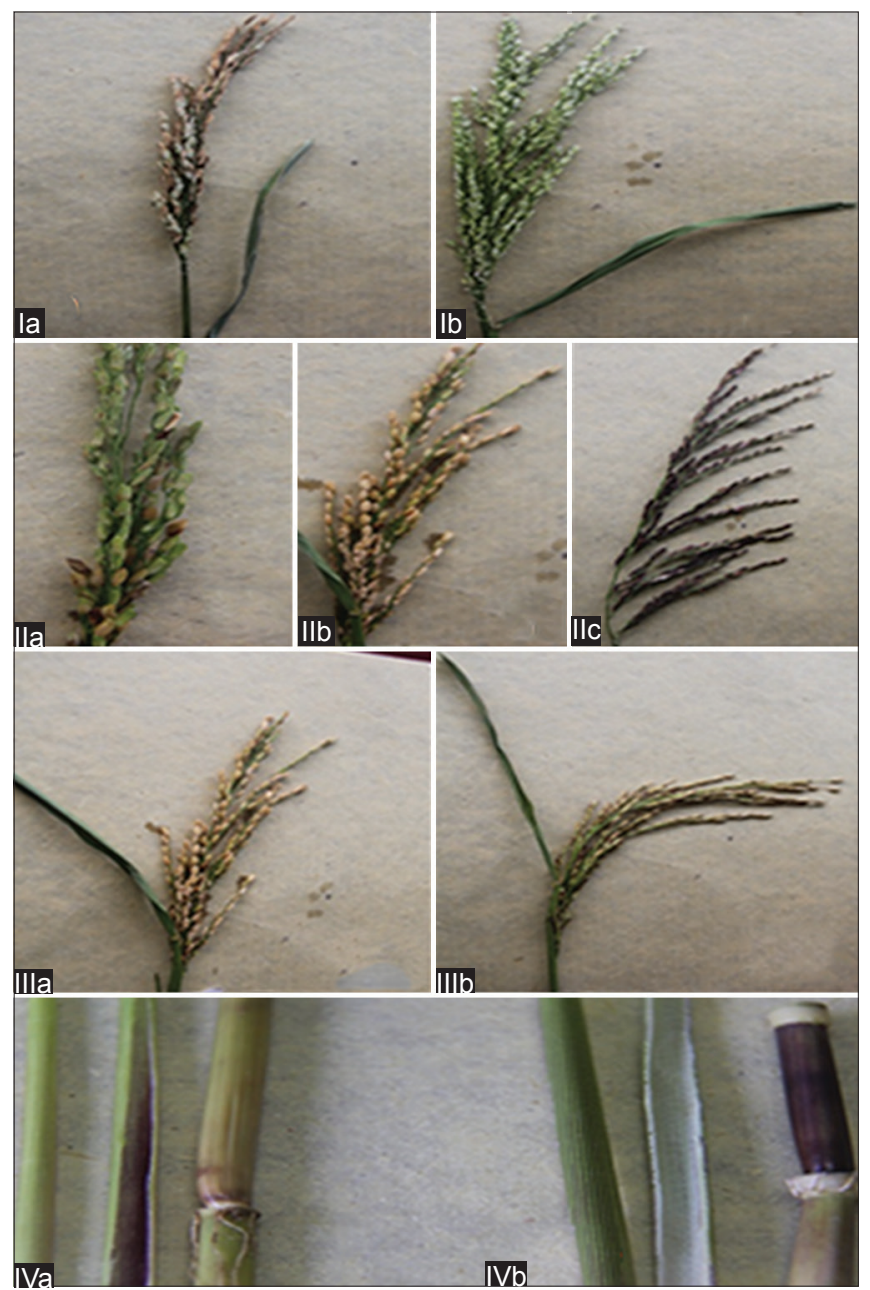

Fig 1. Examples of morphological characters of rice germplasm used as descriptors in this study. I. Flag leaf angle (a. $<45^{\circ}$, b. $45-90^{\circ}$ ); II. Attitude of panicle branch (a. Erect, b. Semi-compact, c. Spreading/ open panicle); III. Panicle axis (a. Semi upright, b. Slightly dropping); IV. Culm color (a. Green, b. Purple).

Table 2: Mean and range values of selected five quantitative morphological traits observed in 60 rice genotypes in this study

\begin{tabular}{lccc}
\hline Traits & Mean \pm SD $(\mathbf{c m})$ & Minimum $(\mathbf{c m})$ & Maximum $(\mathbf{c m})$ \\
\hline Leaf length & $40.15 \pm 12.0$ & 22.30 & 70.30 \\
Leaf width & $0.66 \pm 0.32$ & 0.10 & 1.70 \\
Diameter of & $0.61 \pm 0.09$ & 0.50 & 0.80 \\
basal internode & & & \\
Panicle length & $24.18 \pm 2.89$ & 16.55 & 35.00 \\
Ligule length & $1.80 \pm 0.34$ & 1.25 & 2.60 \\
\hline
\end{tabular}

total genotypes occurred in three main clusters (G1, G2, and G3), in particular, three indica (Isn23-136, Hipa13 and Inpari12) were to be separately from other groups. While the G1 grouped varieties/accessions belonging to indical japonica/ tropical japonica which accommodated overlap characters. The G2 seemed to be distinct group containing indica varieties/accessions (Inpari 30, BMIP19/IPBM-32-13-3 and IR84047-24-3-3-3) and japonica reference cultivar, Nipponbare. These varieties in this group were characterized 
Table 3: Eigenvalues of the first two principal component axes (PC) for the 19 morphological traits used to classify the rice germplasm

\begin{tabular}{lcc}
\hline Characters & \multicolumn{2}{c}{ Principal component axes } \\
\cline { 2 - 3 } & PC1 $^{\mathrm{a}}$ & PC2 $^{\mathrm{b}}$ \\
\hline Leaf blade pubescence & -0.029 & -0.236 \\
Leaf angle & 0.052 & -0.060 \\
Flag leaf angle & -0.201 & -0.203 \\
Collar color & 0 & 0 \\
Auricle color & 0.030 & 0.182 \\
Leaf blade color & 0.315 & 0.180 \\
Leaf sheath color & 0.451 & 0.010 \\
Ligule shape & 0 & 0 \\
Ligule color & 0.346 & 0.334 \\
Leaf length (cm) & -0.095 & 0.152 \\
Leaf width (cm) & -0.014 & 0.456 \\
Culm angle & -0.071 & 0.245 \\
Diameter of basal internode (cm) & 0.356 & -0.294 \\
Culm color & 0.456 & -0.075 \\
Panicle length (cm) & -0.136 & -0.023 \\
Attitude of panicle branch & 0.002 & 0.472 \\
Panicle axis & 0 & 0 \\
Secondary branching of panicle & 0.036 & 0.301 \\
Ligule length (cm) & -0.405 & 0.160 \\
\hline a,b: Eigenvalues of PC1 and PC2 are 2.0 and 1.9, respectively &
\end{tabular}

by intermediate of leaf blade pubescence, semi compact of panicle branch attitude, $<30^{\circ}$ of flag leaf angle and heavy of secondary of branching panicle. The G3 group was predominated by indica varieties (Bio5-AC-Blas/BLB03 = Inpari BLB, D1 red rice, and Code) that showed similar diameter of basal internode within the group.

\section{Genetic relatedness among rice genotypes based on morphological and molecular characters}

Both morphological and molecular data demonstrated the diversity of rice genotypes. Morphological similarities within this rice germplasm in our study indicated genetic relatedness generally supported by SNP variation. An example of SNP pattern surveyed in 60 rice genotypes based on 384 SNPs generated by GenomStudio is shown in Fig. 3. In this cluster pattern, an SNP locus of id6015421 in chromosome 6 with base substitution of $A / G$ revealed homozygote of $\mathrm{AA}$ and $\mathrm{BB}$ in 43 and 15 varieties/ accessions, respectively, and $\mathrm{AB}$ heterozygote was in the remaining varieties observed. This demonstrated that Nipponbare as japonica cultivar reference possessed A allele and IR64 being as indica had its alternate allele in the id6015421 locus (Fig. 3).

The relationships among 60 rice genotypes based on the combined 19 morphological traits and 384 SNPs can be seen in the dendrogram (Fig. 4). The analysis performed two main distinctive clades with a cut off of 2.5. Clade I only contained two varieties, one indica (Inpari 12) and one tropical japonica (Banun). Banun, a tropical japonica variety,

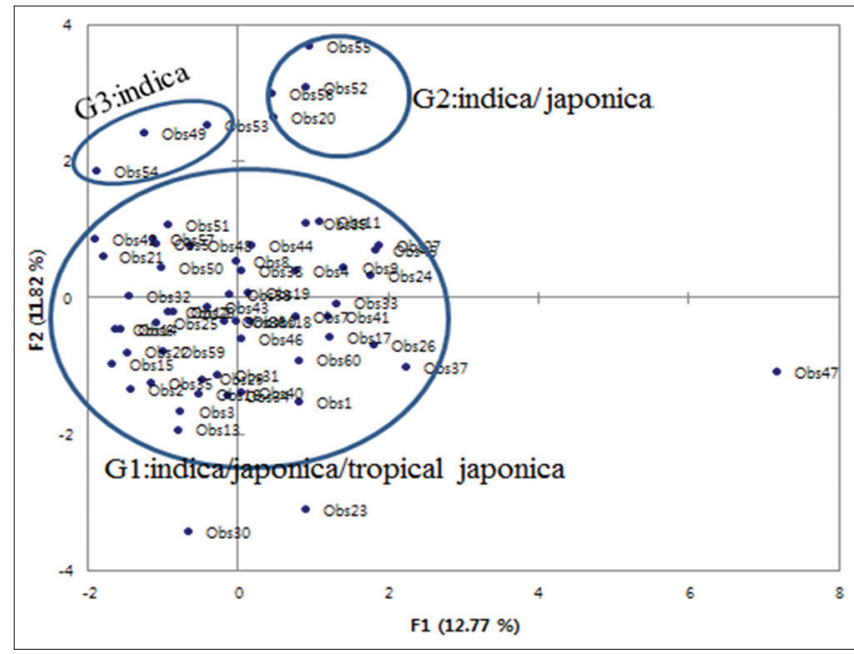

Fig 2. Principal component analysis (PCA) clustering based on morphological similarity of 60 rice accessions.

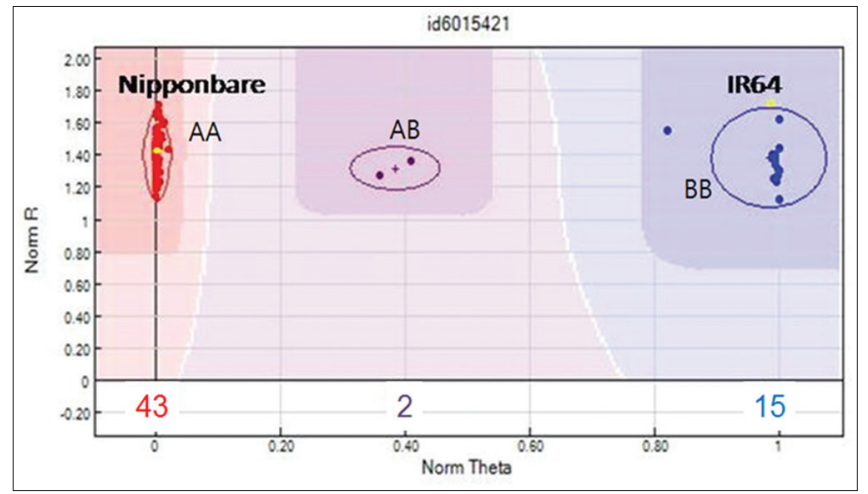

Fig 3. Example of cluster pattern of SNP (id6015421) observed in total 60 rice genotypes based on 384-plex SNP using the GenomeStudio software. Homozygote alleles: AA in red and BB in blue color); heterozygote allele: $A B$ in purple color.

showed different characters on panicle, culm and leaf from indica type. For example, Banun showed greater on leaf length and width, diameter of basal internode, panicle length and ligule length than Inpari12. Qualitative traits like attitude of panicle branch, ligule color, leaf angle and flag leaf angle also differed between the two; however other characters were similar. Their close genetic relationship was supported by the high proportion of same alleles observed on 384 SNP bead array. The clade II grouped most genotypes (58) with different subspecies and genetic background influenced by the pedigree. Three sub-clades were built in the clade II and demonstrated closer relation of each variety/accessions characterized as indica, japonica and tropical japonica in the same sub-clade of II. 1 and II. 2. For example, a japonica variety, BMIP22 was closer to other indica in sub-clade II.1 than the other four japonica varieties (IRBLSH, Kanamaze, Nipponbare and BMIP40) which belonged to the sub-clade II. 2. Interestingly, the sub-clade II. 3 only grouped indica and tropical japonica varieties. Indica 


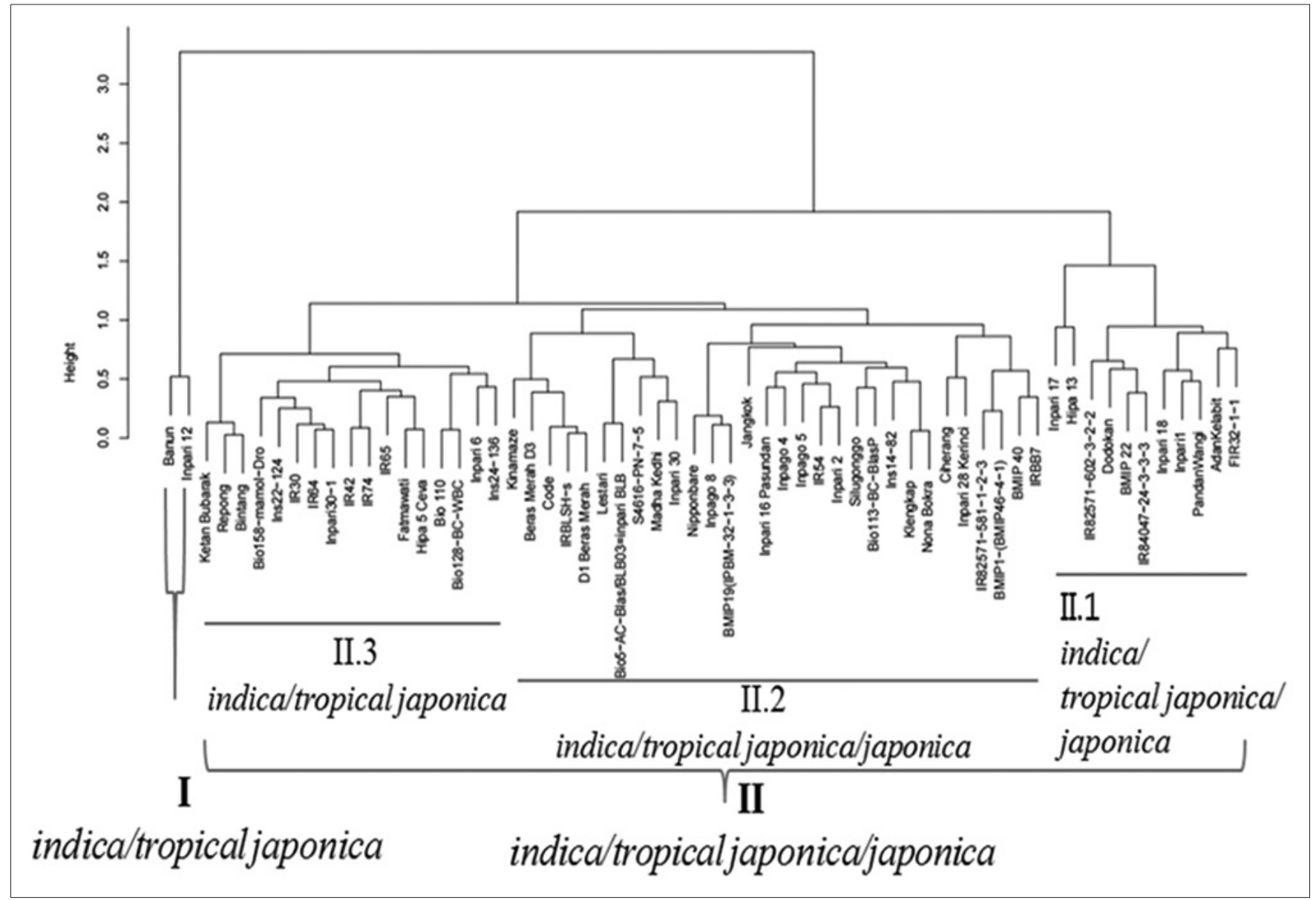

Fig 4. Genetic relationship of 60 rice accessions generated by a combined characterization with morphological traits and 384 SNPs observed. I and II are two major clades, and 1,2 and 3 are three sub-clades belonged to the clade II generated from the Flapjack software.

varieties developed by IRRI tended to be grouped in the same clade (such as IR30, 64, 42, 65 and 74), similarly to upland rice (Inpago 4, 5 and 8), and two red rice accessions ("beras merah D1" and "beras merah D3"). Tropical japonica genotypes also preferentially grouped in the same sub-clade, such as Ketan bubarak, Repong and Bintang, meanwhile Pandanwangi dan Adan Kelabit were on other sub-clade. While, Inpari varieties seemed to be grouped in different sub-clades according to its individual genetic without considering the lowland varieties type.

\section{Association between SNP markers and morphological characters}

The 384 SNP panel desained across 12 chromosomes of rice (Zhao et al., 2010; Utami et al., 2013) was used for association analysis with morphological traits. Total 154 SNPs with diverse base substitutions were significantly associated with 15 morphological traits at P-value threshold of 0.01 . Chromosome 7 contributed greatly with the highest SNP number (21 SNPs) associated with morphological traits and those in chromosome 2 (16 SNPs) and 3 (17 SNPs) were comparable. 48 out of total 154 SNPs were identified to be highly significant associated with 10 morphological traits including leaf blade pubescence, flag leaf angle, leaf length, auricle color, culm angle, culm color, diameter of basal internode, secondary of branching panicle, panicle length and attitude of panicle branch. The number of SNPs significantly associated with morphological characters of rice germplasm is presented in Table 4.

Some SNP markers were found to have common association for several traits. TBGI367899 had associations with leaf blade pubescence, leaf angle and panicle length, and TBGI112858 was highly associated with leaf blade pubescence, auricle color and panicle length. In contrast, specific SNPs were only associated with one morphological traits, such as id10005370 with leaf blade pubescence, and TBGI000824 with culm angle. Among such markers, SNPs had the strongest association with corresponding traits. Eleven of total SNPs had strong association with leaf blade pubescence, of which TBGI367899 with A/G base substitution in chromosome 9 was the strongest $\left(\mathrm{P}\right.$-value $\left.=5.91 \mathrm{E}-09, \mathrm{r}^{2}=0.49\right)$. Two markers of TBGI129684 
Table 4: Number of SNP markers significantly associated with morphological traits observed in 60 Indonesian rice genotypes

\begin{tabular}{|c|c|c|c|c|c|c|c|c|c|c|c|c|c|}
\hline \multirow[t]{2}{*}{ Morphological traits } & \multirow[t]{2}{*}{ Significant SNP numbera } & \multicolumn{12}{|c|}{ Chromosome } \\
\hline & & 1 & 2 & 3 & 4 & 5 & 6 & 7 & 8 & 9 & 10 & 11 & 12 \\
\hline \multicolumn{14}{|l|}{ Qualitative traits } \\
\hline Leaf blade pubescence & 23 & & 4 & 3 & 4 & 2 & 1 & 1 & 2 & 1 & & 3 & 2 \\
\hline Leaf blade color & 3 & & 1 & & & & 1 & & & & & 1 & \\
\hline Flag leaf angle & 17 & 1 & 2 & 1 & 3 & 1 & 1 & 2 & 2 & & 1 & 1 & 2 \\
\hline Leaf angle & 3 & & & & & & & 2 & & & & 1 & \\
\hline Auricle color & 6 & & 2 & 1 & & & & 1 & 1 & & 1 & & \\
\hline Ligule color & 1 & & & & & & & 1 & & & & & \\
\hline Culm angle & 5 & 1 & 1 & & & & & 2 & & & & 1 & \\
\hline Culm color & 3 & 1 & & 1 & & & 1 & & & & & & \\
\hline Secondary of branching panicle & 33 & 3 & 2 & 3 & 2 & 2 & 2 & 5 & 6 & 4 & 1 & 2 & 1 \\
\hline Panicle type & 19 & 1 & & 2 & 3 & 3 & 2 & 3 & & 3 & & 2 & \\
\hline \multicolumn{14}{|l|}{ Quantitative traits } \\
\hline Leaf length & 3 & & 1 & & & & 1 & & 1 & & & & \\
\hline Ligule length & 8 & 1 & & 1 & 1 & 1 & & & & 1 & & & 3 \\
\hline Leaf width & 5 & & & & & & & 2 & 1 & & & & 2 \\
\hline Diameter of basal internode & 9 & 2 & 1 & 1 & 1 & & 1 & 1 & & & 2 & & \\
\hline Panicle length & 17 & 1 & 2 & 4 & 1 & & & 1 & & 4 & 1 & 1 & 2 \\
\hline Total & 154 & 11 & 16 & 17 & 15 & 9 & 9 & 21 & 14 & 13 & 6 & 11 & 12 \\
\hline
\end{tabular}

aSignificant association of SNP marker with morphological traits at $\mathrm{P}<0.01$

and TBGI272460 were strongly associated with culm color and explained high phenotypic variation with the same $r^{2}(0.49)$. Nine of total 33 significant SNP markers were strongly associated with secondary of branching panicle, and SNP id1009867 located in chromosome $1 \mathrm{had}$ the strongest association (P-value $=6.56 \mathrm{E}-05$, $\left.\mathrm{r}^{2}=0.29\right)$. In addition, a number of markers associated with morphological traits were detected to be specific to a variety/accession in respect to leaf, culm of panicle, indicating that there are morphological characters of rice plants supported by molecular characterization that could be used as genetic differentiator. The list of significant SNP markers with their detailed information is shown in Table 5.

\section{DISCUSSION}

Diverse rice germplasm needs a rational use with better knowledge of its characteristic. The presented morphological characters of rice genotypes in Indonesia in our study demonstrated diversity within and among rice sub-species and their genetic relatedness. Similar certain morphology was found among genotypes in the same group such as IR-group, glutinous rice (called as "Ketan"), red rice, and improved varieties etc. Genotypes chosen from different subspecies, ecological area (lowland and upland), glutinous rice and rice were more inherently diverse than they were from a similar environment (Thomson et al., 2009). Quantitative morphological of total 60 genotypes proved their diversity even they possessed similar qualitative characters (Table 2). This rice germplasm which encompassed a wide range of genetic background and ecologically distinct regions probably contained greater genetic diversity as a result of divergent selection pressure. The fact of some improved varieties from indica with given name such as Inpago, Inpari and IR-groups derived from selection by human via breeding or adaptability evaluation represented more genetically identical than subspecies of japonica and tropical japonica. Thus, this study demonstrated the common and specific morphological differences observed among rice collection which is in good agreement with previous study based on morphological traits of wild rice species (Suhartini, 2010), local accessions and improved varieties (Saadah et al., 2013).

Correlation matrix performed among morphological characters could easily assume the relationship between characters. In our study, the most prominent correlations were found on flag leaf angle with leaf angle, leaf sheat pubescence with panicle length, and leaf sheat color with culm color. Such correlation between traits allows for simultaneous selection and utilization of related traits interchangeably in rice. Morphological characterization could be highly considered in routine rice germplasm management for breeding purpose.

PCA is able to measure the importance and contribution of each trait to total variance. In our study, the first 2 component in PCA with eigenvalues of arbitrary set above 0.2 explained the most variations including leaf characters in this rice germplasm. This morphological traits related to leaf could be major descriptor contributing in differentiation of rice germplasm collection (Toshinori, 1991; Shikari et al., 2009). In addition, the contrast between the characters with a positive loaded value in PC1 but a negative loaded value in PC2 suggest that 
Table 5: List of selected 48 SNPs highly significant associated with morphological traits observed in rice germplasm in this study

\begin{tabular}{|c|c|c|c|c|}
\hline Traits & SNP Marker & Chr & P-value ${ }^{\star \star}$ & SNP \\
\hline \multirow[t]{11}{*}{ Leaf blade pubescence } & TBGI367899 & 9 & 5.91E-09 & $\mathrm{A} / \mathrm{G}$ \\
\hline & Id4004654 & 4 & 1.09E-04 & $\mathrm{G} / \mathrm{A}$ \\
\hline & Id12001224 & 12 & 3.23E-04 & $\mathrm{G} / \mathrm{A}$ \\
\hline & Id3006808 & 3 & 4.62E-04 & $\mathrm{G} / \mathrm{A}$ \\
\hline & Id5001470 & 5 & 5.54E-04 & $\mathrm{A} / \mathrm{C}$ \\
\hline & Id7002758 & 7 & $5.64 \mathrm{E}-04$ & $\mathrm{C} / \mathrm{A}$ \\
\hline & TBGI112858 & 2 & 5.81E-04 & $\mathrm{T} / \mathrm{C}$ \\
\hline & TBGI427506 & 11 & 5.96E-04 & $\mathrm{C} / \mathrm{T}$ \\
\hline & TBGI204002 & 4 & 5.96E-04 & $A / G$ \\
\hline & TBGI204006 & 4 & 7.94E-04 & $\mathrm{T} / \mathrm{A}$ \\
\hline & TBGI096830 & 2 & 8.34E-04 & $A / G$ \\
\hline \multirow[t]{4}{*}{ Flag leaf angle } & Id2000096 & 2 & 3.96E-06 & $\mathrm{A} / \mathrm{T}$ \\
\hline & TBGI272620 & 6 & 6.59E-04 & $\mathrm{T} / \mathrm{C}$ \\
\hline & TBGI187461 & 4 & 7.62E-05 & $\mathrm{T} / \mathrm{C}$ \\
\hline & TBGI332082 & 7 & 1.03E-04 & $A / G$ \\
\hline Leaf length & TBGI118590 & 2 & 3.88E-04 & T/A \\
\hline \multirow[t]{2}{*}{ Auricle color } & TBGI117360 & 2 & $6.44 \mathrm{E}-04$ & $\mathrm{G} / \mathrm{A}$ \\
\hline & Id9007763 & 10 & $5.12 \mathrm{E}-04$ & $\mathrm{C} / \mathrm{G}$ \\
\hline \multirow[t]{2}{*}{ Culm angle } & TBGI446467 & 11 & $6.44 \mathrm{E}-04$ & $A / G$ \\
\hline & TBGI336564 & 7 & 4.94E-04 & $\mathrm{C} / \mathrm{G}$ \\
\hline \multirow[t]{3}{*}{ Culm color } & TBGI129684 & 3 & 6.01E-09 & $\mathrm{C} / \mathrm{A}$ \\
\hline & TBGI272460 & 6 & 3.61E-08 & $A / G$ \\
\hline & Id1004591 & 1 & $2.80 \mathrm{E}-06$ & $A / G$ \\
\hline $\begin{array}{l}\text { Diameter of basal } \\
\text { internode }\end{array}$ & Id9007259 & 10 & $9.26 \mathrm{E}-04$ & $A / G$ \\
\hline \multirow{9}{*}{$\begin{array}{l}\text { Secondary of branching } \\
\text { panicle }\end{array}$} & Id1009867 & 1 & $6.56 \mathrm{E}-05$ & $A / G$ \\
\hline & Id9002049 & 9 & 1.05E-04 & $\mathrm{T} / \mathrm{A}$ \\
\hline & TBGI446475 & 11 & $1.55 \mathrm{E}-04$ & $\mathrm{~T} / \mathrm{C}$ \\
\hline & TBGI132691 & 3 & $1.55 \mathrm{E}-04$ & $\mathrm{G} / \mathrm{A}$ \\
\hline & TBGI357779 & 8 & $1.55 \mathrm{E}-04$ & $\mathrm{~A} / \mathrm{T}$ \\
\hline & TBGI336586 & 7 & 3.65E-04 & T/A \\
\hline & Id9002751 & 9 & 3.76E-04 & $\mathrm{C} / \mathrm{A}$ \\
\hline & TBGI336735 & 7 & $9.28 \mathrm{E}-04$ & $\mathrm{~A} / \mathrm{C}$ \\
\hline & TBGI117267 & 2 & $9.44 \mathrm{E}-04$ & $\mathrm{~T} / \mathrm{G}$ \\
\hline \multirow[t]{11}{*}{ Attitude of panicle branch } & Id8002841 & 8 & 7.50E-05 & $\mathrm{C} / \mathrm{G}$ \\
\hline & TBGI235315 & 5 & 1.07E-04 & $G / A$ \\
\hline & TBGI129566 & 3 & $2.81 \mathrm{E}-04$ & $\mathrm{G} / \mathrm{A}$ \\
\hline & TBGI446490 & 11 & $2.95 \mathrm{E}-04$ & $\mathrm{~T} / \mathrm{C}$ \\
\hline & TBGI272517 & 6 & 3.10E-04 & $\mathrm{A} / \mathrm{G}$ \\
\hline & TBGI261579 & 5 & 4.33E-04 & $\mathrm{T} / \mathrm{G}$ \\
\hline & TBGI278839 & 6 & 4.70E-04 & $\mathrm{G} / \mathrm{T}$ \\
\hline & Id3001137 & 3 & 4.71E-04 & T/A \\
\hline & Id6002687 & 7 & 5.22E-04 & $\mathrm{C} / \mathrm{G}$ \\
\hline & TBGI204002 & 4 & 5.33E-04 & $\mathrm{A} / \mathrm{G}$ \\
\hline & TBGI336614 & 7 & 9.17E-04 & $\mathrm{A} / \mathrm{G}$ \\
\hline \multirow[t]{4}{*}{ Panicle length } & TBGI204002 & 4 & $1.49 \mathrm{E}-05$ & $\mathrm{~A} / \mathrm{G}$ \\
\hline & Id9006910 & 10 & 2.17E-04 & $\mathrm{A} / \mathrm{G}$ \\
\hline & TBGI367899 & 9 & $3.40 \mathrm{E}-04$ & $\mathrm{~A} / \mathrm{G}$ \\
\hline & Id8000575 & 9 & 6.61E-04 & $\mathrm{G} / \mathrm{C}$ \\
\hline
\end{tabular}

**Significant level at $\mathrm{P}<0.01$, Chr: Chromosome, SNP: Single nucleotide polymorphism

selected morphological characters could be addressed for characterization and conservation of rice germplasm.
These predominant traits observed in our study like leaf, panicle and culm characters were also found to be important in other Asian countries (Shikari et al., 2009; Sinha and Mishra, 2013; Wijayawardhana et al., 2015).

Based on PCA clustering pattern, the diverse indica varieties revealed distribution of them across clusters and grouped preferentially according to its genetic (Fig. 2). Moreover, group or sub-gene pool within indica rice in tropical and temperate regions were still overlap, indicating seed exchange has been existed for many varieties / accessions, in which diversified rice types were used for various agronomic and cultural practices. Importantly, the morphological changes probably were achieved by the successive rice improvement program (Wijayawardhana et al., 2015). Similar morphological characteristics that are expressed phenotypically could show dissimilarity among accessions in their genomes (Cole-Rodgers et al., 1997). Consequently, genotypes with genetic nearness may be different in the phenotypic characters; therefore genomewide genotyping with custom SNPs was applied to support morphological characterization in our study.

Assorted rice performance in Indonesia has been progressively studied based on phenotypic and molecular characterization, but limited for the use of advantage of SNP markers. Our results were complementary previous reports on desired morpho-agronomical traits in Indonesian rice breeding (Setyawati, 2003; Suhartini, 2010; Rohaeni and Hastini, 2015) that was supported with molecular markers approaches (Thomson et al., 2007; 2009; Utami et al., 2011). 384-plex SNP used in our study has been designed based on previous version of 1536 SNP chip which enabled to identify genetic relationship of 284 accessions into japonical tropical japonica and dominated indica group (Utami et al., 2013). The 384 SNPs variation along with morphological data confirmed a clear separation of rice collection into two main groups (Fig. 4), indical tropical japonica (clade I) and indicaljaponical tropical japonica (clade II). Genomewide diversity, decay of linkage disequilibrium and traits of interest possibly affect the genetic relatedness among varieties within and between subspecies (Thomson et al., 2009). Most of indica varieties were distributed into all major clades and sub-clade, reflecting their similar genetic tendency. These morphological and molecular characters observed in these 60 Indonesian rice genotypes could be relevant to previous reports (Rakshit et al., 2007; McNally et al., 2009; Gustavo and Martinez, 2014).

The presence of tropical japonica accessions closer to indica or japonica groups, suggesting their behavior at molecular level which could be explained by genetic flow in a zone transition between japonica and indica. These rice subspecies seemed to share alleles on the domestication 
process. Japonica and tropical japonica are considered as outcomes of selection for adaptation to different ecology and climate (Garris et al., 2004). Furthermore, genetic make-up and environment could affect the morphology of rice plant (McCouch et al., 1998; Rajapakse et al., 2000). This clustering based on combined morphology and 384 SNPs is relatively comparable with previous studies using 1536 SNPs (Zhao et al., 2010; Utami et al., 2013) and the other 384 SNPs designed somewhere else observed in rice (Tung et al., 2010; Chen et al., 2011; Parida et al., 2012). Overall, the diversity of total rice genotypes used was adequate to provide a valuable resource for association analysis.

The high degree of association between the 154 SNPs with 15 morphological traits demonstrated a high power of these SNPs (Table 5). Particularly, this study highly focused on the vegetative characters of the rice plant, can be used effectively in order to capture a considerable morphological variability associated with Indonesian rice germplasm. The typical morphological characters on leaf, stem and panicle appeared in a certain accessions/varieties, reflecting the existence of its genetic control. This typical morphology along with molecular character could serve as differentiator of rice variety, leading to guide rice breeders that can effectively select morphologically more distinct individuals.

The high significant SNP markers were detected, such as TBGI367899 locus in chromosome 9 associated with leaf blade pubescence, id2000096 with flag leaf angle, TBGI118590 with leaf length, and both TBGI272460 and id1004591 with auricle color etc. Importantly, TBGI204002 (chromosome 4) highly associated with panicle length was located in the region of QTL for panicle length (qPL4), similarly to id1009867 that was in the regions of QTL for culm thickness (AQAW036). Moreover, id1004591 was identified to be near with POLD3-putative DNA polymerase delta complex and a QTL was related to culm thickness (AQDZ006) (Ratho et al., 1991; gramene.org). The SNPs located near or within genes/QTLs of interest need further validation for their useful application. Notably, this high throughput genotyping using 384 SNPs in our study proved their powerful and robustness to scan the genome of Indonesian rice germplasm and finally we were able to obtain potential SNP markers for desired traits. Therefore, the identification of morphological characters which are important to change the rice crop architecture has a greater implication. Since the power association analysis is dependent on both the density of SNPs and the quality of phenotypic data available for analysis (Tung et al., 2010), this result would give a clue of our germplasm panel for genome-wide studies to explore the molecular level of diverse morphological traits in rice (Yang et al., 2015) in Indonesia.

\section{CONCLUSIONS}

Morphological accompanied with high throughput SNP genotyping is more reliable in the evaluation of rice germplasm. The morphology of these rice germplasm could be a performance basis for selection of potential genotypes for further use in rice breeding in Indonesia. 48 SNPs highly significant associated with selected quantitative and qualitative morphological characters are valuable and need a validation. Potential SNP markers in the regions of genes/QTLs of interest namely id1004591, id1009867, TBGI204002 were able to be detected. The implications of these results in our study for rice improvement are based on taking advantage of the genetic variability that exists in the Indonesian rice germplasms.

\section{ACKNOWLEDGEMENTS}

The authors are grateful to the rice genome research team at Indonesian Center for Agricultural Biotechnology and Genetic Resources Research and Development under the Indonesian Agency for Agricultural Research and Development, Indonesia (ICABIOGRAD-IAARD). The authors also give thanks to Nurul Hidayatun for the photo courtesy of rice morphological characters. This research work was supported by the National Indonesian Budget on fiscal year 2014, ICABIOGRAD-IAARD.

\section{Author's contributions}

Lestari P. and Utami D.N. contributed equally to design and conduct the experiment, and analyzed the results. Rosdianti I. was involved to prepare materials, conduct experiment and collect data. Sabran M. assisted in data analysis and edited the manuscript. Lestari P. wrote the manuscript and commented by all authors.

\section{REFERENCES}

Bioversity International, IRRI, WARDA. 2007. Descriptor for Wild and Cultivated Rice, (Oryza spp.), Bioversity International, International Rice Research Institute, WARDA, Africa Rice Center, Rome, Italy, Los Banos, Philippines, , Cotonou, Benin.

Chen, H., H. He, Y. Zou, W. Chen, R. Yu, X. Liu, Y. Yang, Y. M. Gao, J. L. Xu, L. M. Fan, Y. Li, Z. K. Li and X. W. Deng. 2011. Development and application of a set of breeder-friendly SNP markers for genetic analyses and molecular breeding of rice (Oryza sativa L.). Theor. Appl. Genet. 123: 869-879.

Cole-Rodgers, P., D. W. Smith and P. W. Bosland. 1997. A novel statistical approach to analyze genetic resource evaluations using Capsicum as an example. Crop Sci. 37: 1000-1002.

Dancey, C. and J. Reidy. 2004. Statistics Without Maths for Psychology: Using SPSS for Windows. Prentice Hall, London.

Fan, J. B., A. Oliphant, R. Shen, B. G. Kermani, F. Garcia, K. L. Gunderson, M. Hansen, F. Steemers, S. L. Butler, P. Deloukas, L. Galver, S. Hunt, C. McBridge, M. Bibikova, T. Rubano, J. Chen, E. Wickham, D. Doucet, W. Chang, 
D. Campbell, B. Zhang, S. Kruglyak, D. Bentley, J. Haas, P. Rigault, L. Zhou, J. Stuelpnagel and M. S. Chee. 2003. Highly parallel SNP genotyping. Cold spring harb. Symp. Quant. Biol. 68: 69-78.

Franco, T. L. and R. Hidalgo. 2003. Analisis estadistico de datos de caracterizacion morfologica de recursos fitogeneticos. Technical Bulletin No. 8. Instituto Internacional de Recursos Fitogeneticos (IPGRI), Cali, Colombia.

Garris, T., T. H. Coburn, J. Kresovichn and S. McCouch. 2004. Genetic structure and diversity in Oryza sativa L. Genetics. 169: $1631-1638$.

Glaszmann, J. C. 2004. Isozymes and classification of Asian rice varieties. Theor. Appl. Genet. 74: 21-30.

Gustavo, A. L. M. and W. O. Martinez. 2014. Identification of the variatbility of a common bean collection through morphological, physiological, biochemical, and molecular relationships. Agronom. Colombiana. 32: 159-169.

Juansa, A., A. Purwantoro and P. Basunana. 2012. Diversity of rice based on botany-morphology characters and RAPD markers. Vegetalika. 1: 1-11.

McCouch, S. R., G. Kochert, Z. H. Yu, Z. Y. Wang and G. S. Khush. 1998. Molecular mapping of rice chromosomes. Theor. Appl. Genet. 76: 815-829.

McNally, K. L., K. L. Childs, R. Bohner, R. M. Davidson, K. Zhao, V. J. Ulat, G. Zeller, R. M., Clark, D. R. Hoen, T. E. Bureau, R. Stokowski, D. G. Ballinger, K. A. Frazer, D. R. Cox, B. Padhukasahasram, C. D. Bustamante, D. Weigel, D. J. Mackill, R. M. Bruskiewich, G. Rätsch, C. R. Buell, H. Leung and J. E. Leach. 2009. Genome-wide SNP variation reveals relationship among landraces and modern varieties of rice. Proc. Natl. Acad. Sci. USA. 106: 12273-12278.

Milne, I., P. Shaw, G. Stephen, M. Bayer, L. Cardle, W. T. B. Thomas, A. J. Flavel and D. Marshall. 2010. Flapjack-graphical genotype visualization. Bioinformatics. 26(24): 3133-3134.

Parida, S. K., M. Mukerji, A. K. Singh, N. K. Singh and P. Mohapatra. 2012. SNPs in stress-responsive rice genes: validation, genotyping, functional relevance and population structure. BMC Genomics. 13: 426.

Qiagen. 2011. Tissue Lyser Handbook for High-Throughput Disruption of Biological Samples: Purification of DNA From Plant Tissues (Mini Protocols), $2^{\text {nd }}$ ed. 15. Qiagen, Germany, p. 3.

Rabara, R. C., M. C. Ferrer, M. I. C. Calayugan, M. D. Duldulao and J. Jara-Rabara. 2015. Conservation of rice genetic resources for food security. Adv. Food Technol. Nutr. Sci. Open J. SE(1): S51-S56.

Rajapakse, R. M. T., C. A. Sandanayake and B. D. Pathinayake. 2000. Foot prints in rice variety improvement and its impact on rice production in Sri Lanka. Vol. 2. Annual Symposium of the Department of Agriculture, Sri Lanka. Pp. 423-433.

Rakshit, S., A. Rakshit, H. Matsumura, Y. Takahashi, Y. Hasegawa, A. Ito, T. Ishii, N. T. Miyashita and R. Terauchi. 2007. Large scale DNA polymorphism study of Oryza sativa and O. rufipogon reveals the origin and divergence of Asian rice. Theor. Appl. Genet. 114: 731-743.

Ratho, S. N. and S. B. Pradhan. 1991. Cytoplasmically controlled cold tolerance in a cytoplasmic - genetic male sterile line of rice. Euphytica. 58: 241-244.

Rohaeni, W. R. and T. Hastini. 2015. Inventory of local varieties of rice in Ciater, Subang district, West Java. Pros. Sem. Nas. Masy. Biodiv. Indon. 1: 189-193.

Saadah, I. R. and S. Subejo. 2013. Diversity of grain color and rice color of local variety of black rice (Oryza sativa L.) that cultivated by farmer in Sleman, Bantul and Magelang regencies. Vegetalika. 2: 13-20.

Sambrook, J. and D. W. Russel. 2001. Molecular Cloning: A Laboartory Manual, $3^{\text {rd }}$ ed. Cold Spring Harbor Laboratory Press, Cold Spring Harbor, NY.

Sasaki, T. 2002. Rice genomics to understand rice plant as an assembly of genetic codes. Curr. Sci. 83: 834-839.

Setyawati, I. 2003. Biodiversity and traditional knowledge: Rice varieties among the Leppo Ké of Apau Ping. In: Eghenter, C., B. Sellato and G. S. Devung, editors. Social Science Research and Conservation Management in the Interior of Borneo. CIFOR Center for International Forestry Research, Bogor, Indonesia, Pp. 35-48.

Shikari, A. B., G. A. Parray, A. G. Rather and F. A. Sheikh. 2009. Principal component analysis for evaluation of rice (Oryza sativa L.) germplasm. J. Rice Res. 2(1): 16-22.

Singh, N., P. L. Jayaswal, K. Panda, P. Mandal, V. Kumar, B. Singh, S. Mishra, Y. Singh, R. Singh, V. Rai, A. Gupta, T. R. Sharma and N. K. Singh. 2015. Single-copy gene based 50K SNP chip for genetic studies and molecular breeding in rice. Scientific Reports. No. 11600.

Sinha, A. K. and P. K. Mishra. 2013. Morphology based multivariate analysis of phenotypic diversity of landraces of rice (Oryza sativa L.) of Bankura district of West Bengal. J. Crop Weed. 9: 115-121.

Silitonga, T.S. 2010. The use of biotechnology in the characterization, evaluation and utilization in Indonesian rice germplasm. J. Agrobiogen. 6(1): 49-56.

Statistical Analysis System. 2002. SAS. User's Guide. SAS Institute, Cary, p. 525.

Suhartini, T. 2010. Karagaman karakter morfologi plasma nutfah spesies padi liar (Oryza spp.). Bull. Plasma Nutfah. 16: 17-28. (in Indonesian language).

Thomson, M. J., E. Septiningsih, F. Suwardjo, T. Santoso, T. Silitonga and S. McCouch. 2007. Genetic diversity analysis of traditional and improved Indonesian rice (Oryza sativa L.) germplasm using microsatellite markers. Theor. Appl. Genet. 114: 559-568.

Thomson, M. J., N. R. Polato, J. Prasetiyono, K. R. Trijatmiko, T. S. Silitonga and S. R. McCouch. 2009. Genetic diversity of isolated population of Indonesian landraces of rice (Oryza sativa L.) collected in East Kalimantan on the island of Borneo. Rice. 2: 80-92.

Thomson, M. J., K. Zhao, M. Wright, K. L. McNally, H. Leung and S. McCouch. 2010. Development and application of 96-and 384-plex single nucleotide polymorphism (SNP) marker sets for diversity analysis, mapping and marker-assisted selection in rice. In: Innovation and Partnership to Realize Africa's Rice Potential. Second Africa Rice Congress, Barnako, Mali.

Thomson, M. J. 2014. High-throughput SNP genotyping to accelerate crop improvement. Plant Breed. Biotechnol. 2: 195-212.

Tobias, A., I. Molina, H. G. Valera, K. A. Mottaleb and S. Mohanty. 2012. Handbook on Rice Policy in Asia, International Rice Research Institute (IRRI), Philippine.

Toshinori, A. B. E. 1991. Principal component analysis for rice characters relating with plant statues and yield. J. Yamagata Univ. Agric. Sci. 11: 235-247.

Tung, C. W., K. Zhao, M. H. Wright, M. L. Ali, J. Jung, J. Kimball, W. Tyagi, M. J. Thomson, K. McNally, H. Leung, H. Kim, S. N. Ahn, A. Reynolds, B. Scheffler, G. Eizenga, A. McClung, C. Bustamante and S. R. McCouch. 2010. Development of a research platform for dissecting phenotypegenotype association in rice (Oryza spp.) Rice. 3: 205-217.

Utami, D. W., Sutoro, N. Hidayatun, A. Risliawati and I. Hanarida. 2011. Keragaman genetik 96 aksesi plasma nutfah padi berdasarkan 
30 marka SSR terpaut gen pengatur waktu pembungaan (HD genes). J. Agro Biogen. 7: 76-84.

Utami, D. W., I. Rosdianti, P. Lestari, D. Satraywan, H. Rijzaani and I. M. Tasma. 2013. Development and application of 1536-plex single nucleotide polymorphism marker chip for genome wide scanning of Indoensian rice germplasm. Indones. J. Agric. Sci. 14(2): 71-78.

Wijayawardhana, H. C. D., H. M. V. Herath, P. A. Weerasinghe and H. M. D. Herath. 2015. Morphological variation in selected Sri Lankan rice (Oryza sativa L.) accessions in relation to the vegetative parameters. Trop. Agric. Res. 26: 380-389.

Yang, W., Z. Guo, C. Huang, K. Wang, N. Jiang, H. Feng, G. Chen, Q. Liu and L. Xiong. 2015. Genome-wide association study of rice
(Oryza sativa L.) leaf traits with a high-throughput leaf scorer. J. Exp. Bot. DOI: 10.1093/jxb/erv100.

Zeng, Y. W., S. Q. Shen, Z. C. Li, Z. Y. Yang, X. K. Wang, H. L. Zhang and G. S. Wen. 2003. Ecogeographic and Genetic diversity based on morphological character of indigenous rice (O. sativa L.) in Yunnan, China. Resour. Crop Evol. 50: 566-577.

Zhao, K., M. Wright, J. Kimball, G. Eizenga, A. McClung, M. Kovach, W. Tyagi, M. L. Ali, C. W. Tung, A. Reynolds, C. D. Bustamante and S. R. McCouch. 2010. Genomic diversity and introgression in O. sativa reveal the impact of domestication and breeding on the rice genome. PLoS One. 5(5): e10780. DOI: 10.1371/ journal.pone. 0010780 . 